\title{
DIÁLOGOS E SILÊNCIOS NA POESIA PORTUGUESA: DÉCADAS DE 60 A 90
}

\author{
Ida Ferreira Alves* \\ O imaginário lusófono tornou-se, definitivamente, \\ o da pluralidade e da diferença... ${ }^{1}$
}

poesia portuguesa do século XX caracterizou-se por seu
discurso fortemente crítico, questionando insistentemente o trabalho
poético e a identidade nacional a partir da discussão sobre os seus trajetos culturais. Alguns poetas optaram mesmo pela prosa crítica, expondo as balizas do "ofício do verso", divulgando leituras norteadoras de sua formação estética com a avaliação dos caminhos per-seguidos. Assim, no âmbito de uma pesquisa intitulada "Olhares Oblíquos: modos de ver e escrever, na poesia, a cultura portuguesa contemporânea", estamos analisando o trabalho de um conjunto de poetas e seus diálogos com a produção de escritores estrangeiros, principalmente, brasileiros. Pretende-se com esta pesquisa investigar fundamentalmente como a poesia portuguesa contemporânea produzida a partir da década de 60 pensa a criação estética e a cultura nacional em relação às culturas estrangeiras, com ênfase, a brasileira. Por isso, os olhares oblíquos, entendendo esses olhares como modos de ver e escrever a realidade portuguesa nos seus deslocamentos culturais e estéticos. Muitas vezes, é no silenciar de vozes ou no apagamento de imagens que se revelam de forma oblíqua visões de mundo e de culturas. Assim, o desenvolvimento da pesquisa vem demarcando

* Universidade Federal Fluminense/PPRLB.

1 LOURENÇO, E. A nau de Ícaro seguido de imagem e miragem da lusofonia. Lisboa: Gradiva, 1999. p. 112. 
ALVES, I. F. Diálogos e silêncios na poesia portuguesa:...

não só as principais linhas temáticas e críticas que estruturam essa poesia, como também possibilitando compreender que diálogos estéticos ou silêncios culturais persistem na relação entre Portugal, Brasil e a África de expressão portuguesa.

Os primeiros resultados demonstram muito claramente os enlaces entre a poesia portuguesa e a brasileira, principalmente nas décadas de 50 e $60 \mathrm{com}$ progressivo e, já agora, ostensivo silêncio a partir da década de 70. Interessanos, de modo especial, descrever e compreender os impasses e tensões permanentes nas relações luso-brasileiras principalmente frente a um projeto político maior de uma comunidade de língua portuguesa. Ainda que tal problemática já tenha sido enfrentada por pensadores do porte de Eduardo Lourenço, e o seu livro $A$ nau de Ícaro seguido de imagem e miragem da lusofonia (1999) seja excelente exemplo, importa continuar a indagar a extensão e as fronteiras do diálogo cultural, esse sim, elemento indispensável para que qualquer política de lusofonia isenta de nacionalismos exacerbados se efetive em ações concretas e produtivas, acreditando que "esta incompreensão mútua e vivida das nossas duas culturas, as raízes donde ela provém, a reflexão sobre ela e as hipotéticas iniciativas para a minorar, ou viver com ela, sabendo porquê, é que são assunto para debate sério..."

Como um dos nossos objetivos é pensar como tal diálogo se efetivou ou não, na produção poética portuguesa do século XX, e com que perspectiva e compreensão seus poetas buscaram lançar pontes em direção aos brasileiros, para efeito deste artigo, optamos por deter nosso olhar apenas sobre as décadas de 60 e 70. Ora, os anos 60 foram de muita importância na história da poesia portuguesa do século XX, já que foi uma época de confluência de diferentes propostas a confrontar com muita insistência a especificidade da palavra poética e a configuração da própria cultura nacional. Não precisamos aqui relacionar nomes e obras de relevo, mas vale ressaltar que a poesia, em Portugal, chegava a esses anos com o fardo do compromisso sócio-político herdado da orientação neo-realista e com a ânsia da renovação estética, incentivada pela movimentação surrealista, por meio de experimentalismos formais, ou pela afirmação do sujeito na experiência narrativa a dar conta do cotidiano e do mundo. Nessa década, Ruy Belo, Herberto Helder e os jovens poetas de Poesia 61 publicavam seus primeiros livros; os criadores da poesia experimental, como E. M. de Mello e Castro e Ana Haterly apresentavam sua teorização e objetos poéticos; poetas como Manuel Alegre e Fernando Assis Pacheco enfrentavam o colonialismo e a velha questão do Império; as vozes de Luiza Neto Jorge e Maria Teresa Horta afirmavam uma poesia de libertação do corpo, social e sexualmente considerado,

2 LOURENÇO, op. cit., p. 142. 
com denúncia corajosa dos discursos hierárquicos a impedir o prazer do corpo e a liberdade de expressão. Como vemos por meio desse panorama mínimo, é um momento plural propício ao debate sobre a intervenção da escrita literária na realidade portuguesa opressora e oprimida.

Sem dúvida, dentre os poetas que a crítica vem afirmando como essenciais para compreensão dessa época, desejamos destacar Ruy Belo. Falecido em 1978, com apenas 45 anos, deixou não só uma importante obra poética, ainda pouco examinada nos estudos brasileiros de poesia portuguesa, como também uma obra crítica sobre o trabalho de poesia e a vida mental de seu país, que precisa ser mais conhecida, como é o caso de seu livro intitulado Na Senda da Poesia, publicado em 1969. Trata-se da reunião de "escritos de bem diversa índole, aglutinados pela circunstância comum de todos eles, sem excepção, versarem sobre o fenómeno poético", pois "seja como for, sempre nos interessou a crítica literária como meditação sobre a própria poesia e, por outro lado, sempre nos pareceu que o seu exercício podia esclarecer ou iluminar em certa medida esse dom poético que afinal deve existir, quanto mais não seja, a nortear o ofício." "3 Poeta admirado por seus pares, e paradigmático para os que começaram a publicar na década de 70, sua produção crítica evidencia bem uma formação de leitor de poesia no Portugal dos anos 50 e 60, época, aliás, em que a escrita poética parecia estar no centro de todas as atenções teóricas e analíticas. Mas, deixemos na sombra a discussão do fenômeno poético que Ruy Belo intenta realizar nesses escritos, para destacar em $\mathrm{Na}$ Senda da Poesia a atenção que o poeta crítico dá à questão de influência em poesia e aos valores que, por meio dela, se revelam. Examinando essa escrita atenta e especializada de poeta, perguntamos: com que olhar a poesia brasileira é examinada num momento de enfrentamento de tradições poéticas e na construção de caminhos renovadores da poesia de língua portuguesa?

Lembremos que Ruy Belo havia freqüentado a Faculdade de Letras de Lisboa e ali fora aluno de Jacinto do Prado Coelho e dos poetas, hoje consagrados, Vitorino Nemésio e David Mourão-Ferreira, nomes maiores do magistério de Letras, que, naquela época, estavam também em contato mais próximo com a poesia produzida no outro lado do Atlântico. Certamente vem desse contato mediador, o interesse de leitor que Ruy Belo demonstra ter sobre a poesia brasileira e a sua vontade de pensar criticamente essa produção, ainda que não o faça amiúde. Principalmente, esse interesse revela-se na absorção de experiências que estarão muito mais presentes na sua própria prática poética, do que nos

3 BELO, R. Obra poética. Lisboa: Presença, 1984. v. 3, p. 11. 
ALVES, I. F. Diálogos e silêncios na poesia portuguesa:...

textos ensaísticos, como no caso da poesia de Jorge de Lima a ecoar em seus versos. Aliás, sobre o poeta brasileiro, relembra Ruy Belo:

Conservo (...) a primeira edição do Livro de Sonetos que Jorge de Lima trouxe, já completamente elaborado, de uma clínica do Rio de Janeiro onde dera entrada para uma cura de sono, primeira edição com dedicatória autógrafa do vate brasileiro para Forjaz Trigueiros e por este endossada a mim e dentro, num papel solto, autógrafa também, uma Verborreia poeticástrica do mestre recentemente desaparecido que começa: "A minha emoção gelada / Foi há muito aproximada..." ${ }^{4}$

Nos textos em prosa, o poeta se declara constantemente um leitor e isso significa a abertura para receber o outro na sua diferença e incorporá-lo à sua própria perspectiva de trabalho. Vale transcrever o que disse o poeta em seu artigo "As influências em poesia":

A influência é um acto de homenagem porque só se é influenciado por um poeta que se admira. As obras singulares intercomunicam entre si e a arte é um grande empreendimento colectivo, como por exemplo a construção civil. Se se pode dizer que a poesia de um determinado país avança é porque os novos poetas convivem e medem forças com vozes extintas. A esta luz, não só a crítica é uma leitura vivificadora de determinada obra; também o é a poesia. $^{5}$

Acompanhando as considerações de Ruy Belo, vemos como seu conhecimento literário foi se constituindo e que valores lhe eram essenciais. Por exemplo, indagado se nunca tentara ficção, o poeta responde que lera Fernando Namora e Jorge Amado, autores modelares da narrativa de língua portuguesa

4 BELO, R. Homem de palavra [s]. 5. ed. Lisboa: Presença, 1997. p. 29.

5 BELO, Obra poética, op. cit., p. 245. 
naquele momento. Mas, diz o poeta não admirar o brasileiro, ainda mais que, em contato pessoal, Jorge Amado lhe desejara "êxito", e essa noção de êxito ligada pragmaticamente a sucesso editorial chocara o poeta que vivenciava a literatura como compromisso ético num país pobre e aprisionado. Assim, sem o afirmar claramente, Ruy Belo nos diz que o afamado escritor brasileiro não cumprira para ele o papel que esperava de um escritor que valesse a pena: ser um mestre.

Aliás, sobre isso, permitam-nos um parêntese: em outro contexto, Eduardo Lourenço também avaliará o que representou a obra de Jorge Amado para os portugueses e como a transformação de sua escrita, assumindo uma literatura cada vez mais lúdica e euforizante, contrastava com a "totalidade dramática ou vagamente trágica dos seus Mar Morto, Terras do Sem Fim, de tanto significado para os escritores portugueses de sua geração." ${ }^{\circ} \mathrm{Na}$ sua perspectiva, tal mudança correspondia ao anseio brasileiro de não se confrontar com o trágico, reconhecendo-se numa "imagem mítica do seu destino como realidade mestiça, sensual, triunfalista, inocentemente amoral, perfeita e unicamente humana", afastando-se da dignidade metafísica tão valorizada pelos portugueses. Dignidade que só Guimarães Rosa voltaria a encontrar, segundo Eduardo Lourenço.

Voltando ao campo da poesia, Ruy Belo defende com muita clareza um critério de valor em relação à influência entre escritores, afirmando que "todo o poeta que faz obra válida modifica a poesia do passado." ${ }^{8}$ Daí a importância de que se reveste o comentário breve sobre Carlos Drummond de Andrade "o leitor de poesia em língua portuguesa só pode ler bem Camões se antes tiver lido Carlos Drummond de Andrade." "No entanto, é sobre Manuel Bandeira que o poeta português escreverá mais extensamente. Visto como um precursor, Bandeira representa a extrema consciência do trabalho poético, a habilidade técnica de, sob a aparência de simplicidade e espontaneidade do verso, cumprir as exigências da poesia moderna. Comenta Ruy Belo: "Em poesia de língua portuguesa, outros puseram em prática o verso livre mas talvez ninguém como Manuel Bandeira o tenha dignificado tanto, pela constância e pelo progressivo acerto do seu trabalho." $" 10$

A atenção dada à poesia de Bandeira, em dois ensaios de extensão mediana, acaba por revelar as próprias tensões por que passava a poesia

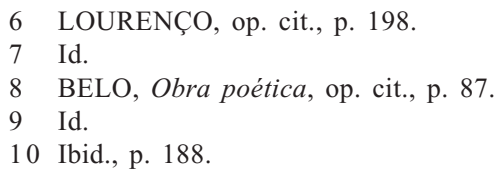


ALVES, I. F. Diálogos e silêncios na poesia portuguesa:...

portuguesa nos anos 60 . O projeto neo-realista com seu compromisso de engajamento e sua visão funcional da arte chocava-se com a ânsia libertária de propostas estéticas que desejavam um lirismo renovado. Interessante que o poeta português destaca a afirmação muito conhecida de Manuel Bandeira a respeito de ser "poeta menor" por não fazer poesia social. A partir disso, enfatiza a importância da escolha de Bandeira, mostrando que seu lirismo reunia as condições fundamentais para uma poesia universal: "sentidos, inteligência e vontade". De um certo ponto de vista, parecia responder aos controladores poéticos de plantão, ainda mais quando sabemos que os textos sobre o poeta brasileiro tiveram divulgação imediata (foram publicados em Rumo, n. ${ }^{\circ} 118$, de dezembro de 1966 e $O$ Tempo e o Modo, $n{ }^{\text {os }}$ 62-63, correspondente a julho/ agosto de 1968), e um deles se intitulava exatamente "Manuel Bandeira ou como um poeta se faz".

Bandeira é, assim, um paradigma de poeta que soube aliar o moderno com a tradição lírica mais original de língua portuguesa e Ruy Belo destaca as seguintes palavras do brasileiro, que bem antes enfrentara tensões semelhantes às que experimentavam os poetas portugueses dos anos 60: "Muitas vezes agora me toma um enjoo mortal da poesia: os discursivos me dão impressão de terra exausta; os concretistas de eternos pesquisadores que não acham nada. Em tais ocasiões me defendo recorrendo à poesia dos velhos cancioneiros galaico-portugueses. Sua inefável frescura me desaltera, me recoloca no amor da poesia." $" 11$

Vemos que nomeando claramente a importância de Manuel Bandeira e Carlos Drummond de Andrade, por exemplo, Ruy Belo testemunha como, na sua contemporaneidade, sob perspectiva crítica, a poética brasileira era parceira na discussão dos caminhos da poesia moderna. Afirma o poeta português:

A influência é um local de confronto. Para experimentar as suas forças um poeta enxerta na sua obra um segmento alheio, oriundo de qualquer domínio maxime da poesia nacional ou estrangeira. E a árvore, que confinada aos seus próprios limites estaria condenada à morte ou à menoridade, ensaia novos ramos, percorridos pela mesma seiva. A influência é também um meio de convívio. A poesia é a melhor sala de que o poeta dispõe para

11 BELO, Obra poética, op. cit., p. 195. 
conviver com os seus contemporâneos e a única sala onde pode receber e ouvir a voz dos antigos. ${ }^{12}$

Então, ainda estavam presentes nessa sala os poetas brasileiros como Carlos Drummond de Andrade, Cecília Meireles, Vinícius de Moraes, Jorge de Lima, Murilo Mendes, João Cabral de Melo Neto, assim como também estavam presentes nas salas de outros poetas e críticos portugueses como Adolfo Casais Monteiro, Jorge de Sena, Vitorino Nemésio, David Mourão-Ferreira, Sophia de Melo Breyner Andresen e António Ramos Rosa. Mas, bastou mais uma década, para que esse convívio diminuísse sensivelmente.

Falando agora de poetas e poetas-críticos que começaram a publicar em 70 e já se tornaram hoje vozes destacadas no panorama da poesia portuguesa mais recente, nota-se a falta de convívio brasileiro e o adensamento de um silêncio apenas rompido por encontros muito pontuais e muito pessoais. Examinando obras críticas de poetas como Joaquim Manuel Magalhães, João Miguel Fernandes Jorge e Nuno Júdice, nota-se que a poesia brasileira não é mais objeto de leitura e compreensão, que não há diálogo, pior, nem mesmo interesse nisso. Na escrita poética dos anos 70, 80 e 90, então, raros são os poemas de motivação brasileira ${ }^{13}$ e, quando ocorrem, surgem de uma experiência rápida de viagem, um olhar em trânsito, que não chega a configurar o desejo de compreender o outro ou de estabelecer um encontro cultural mais aprofundado. Sob essa perspectiva, há, aliás, um significativo poema de Joaquim Manuel Magalhães marcando o olhar de desprezo por um "poeta" brasileiro, visto apenas como um explorador de palavras, fútil na sua vaidade e irrelevante na sua presença em Portugal, com uma "meia língua" aos ouvidos portugueses:

O poeta era brasileiro e de turismo.

Na meia língua dos dois ensaboou-me com um baião de galanteria.

Loas de grasnar a tolo e, é claro, to talmente verdade a sua ladainha.

12 BELO, Obra poética, op. cit., p. 245.

13 Lembremos, por exemplo, o conjunto de poemas Visitação, parte III, de António Franco Alexandre, 1." edição de 1983, em que o sujeito lírico se defronta com o espaço brasileiro, principalmente, do Nordeste. 
ALVES, I. F. Diálogos e silêncios na poesia portuguesa:...

Emplumei-me de rubores a consentir tudo o que requeria: introduções, selecções, montras de livraria. Um festim de recalques borbulhava compensado: "Faça o que quiser. A si eu autorizo."

O brasileiro resfolegava de elogios. Ganhara as férias, tinha pronta a lista da antologia e mesmo em editora de segunda-feira já palmara em troca agradecida um piqueno florilégio luso de versos seus.

Aviões passavam para bem mais longe às seis da tarde desse dia.

Calcados pela vigarice, no super mercado de abraços, esgueirámo-nos cada um para a sua maravilha. ${ }^{14}$

Esse afastamento, acentuado a partir dos anos 70, implica naturalmente algumas questões: não haverá no panorama da poesia brasileira contemporânea novas vozes fortes e instigantes o suficiente para provocar a renovação do diálogo? Ou a poesia portuguesa, refletindo as exigências político-econômicas de um Portugal integrado na Comunidade Européia, precisa voltar-se inteiramente para esse espaço e com ele confrontar-se em pé de igualdade, sem tempo a perder com a utopia da lusofonia? Sem dúvida, basta folhear diferentes livros de poesia dos mais diversos poetas portugueses contemporâneos para notar que, em suas "salas de convívio", estão poetas alemães, ingleses, franceses e espanhóis, principalmente, e que isso sinaliza um Portugal ainda desejoso de um lugar cultural europeu representativo, definindo, para si, um modo (há muito perseguido) de ser "Europa", e não periferia à beira-mar.

Talvez, cansados de lançar seu olhar para o Atlântico, em busca de utopias de grandeza - e a lusofonia seria, sob essa perspectiva, a última utopia - os poetas portugueses de agora tenham assumido definitivamente uma tradição de raiz, e por isso virem as costas a uma realidade de língua portuguesa muito diferente da sua, a qual, por sua vez, sempre repudiou o olhar português em prol da afirmação de diferença e independência nacional. A cultura brasileira é uma

14 MagalhãeS, J. M. Alguns livros reunidos. Lisboa: Contexto, 1987. p. 117. 
cultura outra, que num som semelhante fala de um mundo muito diferente, com outros valores, com outros modelos, com outra memória. Percebemos que, apesar de todo esforço aqui e lá para manutenção do diálogo - e pensamos, em âmbito cultural, na circulação (muito deficiente) do livro, o trânsito (eventual) de escritores em tempo de congressos e Bienais, o encontro (insuficiente) de críticos e professores, parcerias como a da revista de poesia Inimigo Rumor com direção luso-brasileira, a partir do número 11 (novembro de 2001) e a persistência universitária dos estudos portugueses - caminhamos irremediavelmente, mesmo em termos do imaginário cultural, espaço tão necessário para fundar imagens identitárias, para o desencontro ou, mais gravemente, para a indiferença, dura forma de silenciar o outro em nós.

Parece-nos que o silêncio sobre a poesia brasileira na produção poética portuguesa mais atual (e as exceções não invalidam a reflexão) é a manifestação simbólica de um desejo de afirmação européia ainda relacionado a um projeto tardio de identidade moderna. Como bem disse o filósofo Manuel Maria Carrilho, quando Ministro da Cultura, em Portugal, no final da década de 90: “o problema português não é o de atingir ou não atingir a pós-modernidade, mas, sim, o de desenvolver os valores da modernidade." 15 Os poetas portugueses, em tempo de crítica, voltam-se, portanto, para essa questão, pensando seus dilemas e suas exigências. Frente a isso, a relação Portugal-Brasil se limita, cada vez mais, a imagens do passado, aos desencontros constantes e às viagens de turismo.

\section{RESUMO}

Este trabalho analisa a poesia portuguesa contemporânea: décadas de 60 a 90 e a relação de leitura e crítica com a literatura brasileira moderna. A importância do trabalho crítico de um poeta como Ruy Belo, agente de mediação entre a poética portuguesa e a brasileira, e a mudança de perspectiva cultural dos poetas que começam a publicar nos anos 70. Aborda também a questão da lusofonia e seus impasses culturais.

Palavras-chave: Poesia portuguesa contemporânea, relações luso-brasileiras, cultura lusófona.

15 Apud COELHO, E. P. O cálculo das sombras. Lisboa: Asa, 1997. p. 99. 


\begin{abstract}
Modern Portuguese Poetry: from the 60's to the 90's and how it is related to the Modern Brazilian Literature in terms of interpretation and critical study. The importance of the critical work of a poet such as Ruy Belo, mediator between the Portuguese and the Brazilian poetry, as well as the change in cultural perspective of poets who start to publish in the 70's. The lusophony and its cultural barriers.

culture.

Key-words: Modern Portuguese poetry, Brazilian-Portuguese relations, lusophonic
\end{abstract}

\title{
REFERÊNCIAS
}

ALEXANDRE, A. F. Visitação. In: ALEXANDRE, A. F. Poemas. Lisboa: Assírio \& Alvim, 1996.

BELO, R. Homem de palavra [s]. 5. ed., Lisboa: Presença, 1997.

Obra poética de. Lisboa: Presença, 1986. Org. e notas de Joaquim Manuel Magalhães e Maria Jorge Vilar de Figueiredo. v. 3.

COELHO, E. P. O cálculo das sombras. Lisboa: Asa, 1997.

LOURENÇO, E. A nau de Ícaro seguido de imagem e miragem da lusofonia. Lisboa: Gradiva, 1999.

MAGALHÃES, J. M. Alguns livros reunidos. Lisboa: Contexto, 1987. 